\title{
REVIEW
}

\section{Clinical review: Brain-body temperature differences in adults with severe traumatic brain injury}

\author{
Charmaine Childs ${ }^{1 *}$ and Kueh Wern Lunn²
}

\begin{abstract}
Surrogate or 'proxy' measures of brain temperature are used in the routine management of patients with brain damage. The prevailing view is that the brain is 'hotter' than the body. The polarity and magnitude of temperature differences between brain and body, however, remains unclear after severe traumatic brain injury (TBI). The focus of this systematic review is on the adult patient admitted to intensive/neurocritical care with a diagnosis of severe TBI (Glasgow Coma Scale score of less than 8). The review considered studies that measured brain temperature and core body temperature. Articles published in English from the years 1980 to 2012 were searched in databases, CINAHL, PubMed, Scopus, Web of Science, Science Direct, Ovid SP, Mednar and ProQuest Dissertations \& Theses Database. For the review, publications of randomised controlled trials, non-randomised controlled trials, before and after studies, cohort studies, case-control studies and descriptive studies were considered for inclusion. Of 2,391 records identified via the search strategies, 37 were retrieved for detailed examination (including two via hand searching). Fifteen were reviewed and assessed for methodological quality. Eleven studies were included in the systematic review providing 15 brain-core body temperature comparisons. The direction of mean brain-body temperature differences was positive (brain higher than body temperature) and negative (brain lower than body temperature). Hypothermia is associated with large brain-body temperature differences. Brain temperature cannot be predicted reliably from core body temperature. Concurrent monitoring of brain and body temperature is recommended in patients where risk of temperature-related neuronal damage is a cause for clinical concern and when deliberate induction of below-normal body temperature is instituted.
\end{abstract}

\section{Introduction}

Brain temperature monitoring has advanced since Benzinger and colleagues [1] first used the tympanum as a 'proxy' for brain temperature monitoring. It was not until 1990 that Mellergard and colleagues [2] performed the first human invasive, continuous monitoring of intracranial temperature via an intraventricular thermocouple. Since then, several types of invasive brain temperature measurement devices have been developed to investigate temperature in different parts of the human brain. The measurement of brain temperature is now more usually made in brain tissue (parenchyma), cerebral ventricle or in the subdural space using a thermistor. Patients who may benefit from continuous brain temperature

*Correspondence: nurcc@nus.edu.sg; charmaine_childs@hotmail.co.uk ${ }^{1}$ Clinical Research Centre, Block MD11, Level 2, Yong Loo Lin School of Medicine, National University of Singapore, 10 Medical Drive, Singapore 117597 Full list of author information is available at the end of the article monitoring include patients with severe traumatic brain injury (TBI).

For the purpose of this systematic review, severe TBI is defined as 'a brain injury incurred by a traumatic mechanism of injury with a resultant level of consciousness categorised by a Glasgow Coma Scale (GCS) score of 8 or lower' [3]. TBI affects two to three million people in the USA each year [4]. In South East Asia (Singapore) $50 \%$ of all trauma-related mortality is due to severe TBI [5].

Of the known clinical and physiological events contributing to secondary ischaemic damage in vulnerable (survivable) neurones, raised temperature (due to fever or to hyperthermia) is a potentially avoidable risk factor. The problem is that the temperature of injured tissue is seldom measured [6]. Rather, the customary assumption is that temperature, wherever it may be measured on or in the body, provides sufficient reliability and reproducibility to estimate brain temperature. During aggressive (surface or invasive) therapies directed towards induction 
of hypothermia the temperature of the 'target' organ is just a matter of guesswork. Proper and robust assessment and management of patients undergoing therapeutic temperature management warrant an objective assessment of the treatment (rate and speed of brain temperature reduction). Currently, temperature measurement of the oral cavity, skin folds (axilla, groin), tympanum, and rectum are the sites most commonly used in neurocritical care [7].

The overall aim of this systematic review was to critically appraise, synthesise and present the best available evidence that core body temperature is a reliable proxy for brain temperature in adult patients with severe TBI. Before undertaking this systematic review, library databases of the Cochrane Collaboration and of the Joanna Briggs Institute (JBI) were searched. No previous systematic reviews on the topic had been undertaken. Our objective, therefore, was to close the gap in knowledge about the reliability of assuming brain temperature values from measurements made at other body sites.

\section{Methods}

This paper is abridged and based on a detailed review published previously in the JBI Library of Systematic Reviews [8]. Ethical approval was not required to undertake the review.

\section{Search strategy}

Literature published in languages other than English were excluded from the review.

The search strategy aimed to retrieve published and unpublished studies written in the English language during the last 32 years (1980 to 2012). The justification for this publication restriction is because invasive brain temperature measurement in humans was not available before 1980. A three-step search strategy was utilized. An initial (limited) search of PubMed and CINAHL was undertaken followed by analysis of the text words contained in the title and abstract and index terms used to describe the article. A second search using all identified keywords and index terms was undertaken for all included databases. The reference list of all identified reports and articles was then searched for additional studies. The initial keywords were categorised as three concepts (Table 1). The databases searched were: CINAHL, PubMed, Scopus, Web of Science, Science Direct, Ovid SP, Mednar, ProQuest Dissertations \& Theses Database. For a full list of search terms used in this review, see [8].

\section{Inclusion criteria}

Studies of male and female adult patients (in this review, aged 15 years and above) admitted to an adult ICU with
Table 1. Keyword categories: development of search categories and search terms

\begin{tabular}{ll}
\hline Concepts & Keywords \\
\hline Concept 1: Brain temperature & Epidural temperature \\
& Ventricular temperature \\
& Intraparenchymal temperature \\
& Cortical temperature \\
& Intraventricular temperature \\
& Jugular bulb temperature \\
& Subdural temperature \\
& Brain temperature \\
& Core temperature \\
& Body temperature \\
Concept 2: Core body temperature & Core body temperature \\
& Pulmonary artery temperature \\
& Esophageal temperature \\
& Oesophageal temperature \\
Bladder temperature \\
Tympanic temperature \\
Temporal artery temperature \\
Rectal temperature \\
Severe traumatic brain injury \\
Traumatic brain injury \\
TBl \\
Brain injury \\
Head injury \\
\\
\end{tabular}

the diagnosis of severe TBI (GCS $\leq 8)$ were included. Evidence of brain and body temperature monitoring during the study was a requirement for inclusion. All other conditions of acquired brain damage (for example, stroke, brain tumour, subarachnoid haemorrhage) were excluded from this review as were publications with brain temperature monitoring performed on non-human subjects.

\section{Selection of studies}

The review considered any randomised controlled trial (RCT). In the absence of RCTs, other research designs non-randomised controlled trials, pre-test-post-test studies, cohort studies, case-control studies, and descriptive studies - were considered for inclusion.

\section{Methods of temperature measurement}

The review included studies reporting concurrent brain temperature and core body temperature measurements. The direct brain temperature monitoring methods include subdural temperature, intraventricular temperature, and tissue (parenchyma) temperature. Indirect 
methods (jugular bulb temperature) for brain temperature estimation were also included [9]. Core body temperature measurement sites include tympanum, temporal artery, rectal, bladder, oesophageal and pulmonary artery sites.

\section{Assessment of methodological quality}

The publications selected for retrieval were assessed for methodological validity by two independent reviewers (CC and KWL) before data extraction. The JBI-MAStARI critical appraisal tool was used. However, in view of the specific review question, neither the standard nor bespoke appraisal tools available (the latter for temperature method comparison [10]) from JBI were appropriate. In this review, where measurement of temperature per se at two different body sites was made predominately by electronic thermometry systems, a modification of the appraisal tool of Craig and colleagues [10] was developed and approved (Figure 1) by the JBI [8]. As there were no disagreements in the assessment of methodological quality of the retrieved studies, a third, moderator, reviewer was not required.

\section{Data extraction and data synthesis}

Data were extracted from papers included in the review using a bespoke data extraction tool (Figure 2) [8]. The extraction of data included specific details of therapeutic temperature interventions, study population and methods and outcomes of significance to the review question and specific objectives. In extracting numeric data, and where mean values or confidence interval $(\mathrm{CI})$ was not provided by the original study authors, $\mathrm{CI}(\overline{\mathrm{x}} \pm 1.96(\mathrm{SD} / \sqrt{ } \mathrm{n}))$ was calculated from raw data where available. For data synthesis, statistical pooling was not possible; therefore, findings are presented in narrative form.

\section{Results}

\section{Search results}

The literature search yielded 2,391 articles (Figure 3). Thirty-seven studies were retrieved as 'eligible. After filtering the title and abstract, 22 were excluded following review of the full text. Of these, 15 were assessed for methodological quality. Eleven studies met the criteria for inclusion and were included in the review (Table 2).

\section{Study characteristics}

The sample size of the 11 studies included in this review ranged from 7 [11] to 58 [12], giving a total of 272 patients aged 15 years [13] to 80 years [14,15]. The publications were descriptive studies (Table 3) conducted in the USA [12,16-18], the UK [14,19], Japan [13,20], Taiwan [15], Austria [11], or People's Republic of China [21]. Patients were recruited from an adult ICU. Brain injury was described as severe TBI $[11,13-15,17,19,20]$ or severe head injury $[12,16,18,21]$. At the time of brain temperature monitoring all patients in the 11 studies had a GCS of $\leq 8$.

One study only used a prospective methodological approach in the study design to power the sample size sufficiently to identify a scale of difference between brain and body temperature [19]. The remainder were designed for observational 'convenience' or pragmatic sampling.

Seven studies were designed to investigate the difference between brain temperature and core temperature per se [11,14-16,18-20]. By contrast, differences between brain temperature and core temperature were not the primary objective of the remainder $[12,13,17,21]$. Even so, the latter studies were included because data of the temperature gradient between brain and core was reported.

Four studies investigated brain and core body temperature under standard routine care without performing any thermoregulatory interventions $[14,15,18,19]$ (Table 2). Two performed therapeutic temperature management to a target of 'normothermia' [11,17] while in four studies therapeutic hypothermia was induced $[13,16,20,21]$. One study investigated temperature of patients with both induced normothermia and induced hypothermia [12]. All 11 studies provided data on brain temperature and core body temperature measurements. Temperature measurement began during the first 48 hours after injury, providing parity in the onset and temporal profile of the measurements.

Fifteen different brain-body temperature measurement comparisons were reported in the 11 studies. For comparison with brain temperature, measured in cerebral ventricle $[16,17]$, subdural space [13] and tissue (parenchyma) $[11,12,14,15,18-21]$, core body temperature was measured in rectum $[12,13,15-19,21]$, bladder $[11,16,20]$, jugular vein [13], temporal artery $[14,15]$ and tympanic membrane [14]. Calibration of thermometers was performed in five studies only $[15,16,18-20]$. The remaining studies did not report any calibration procedures.

\section{Statistical analyses}

In the respective papers, descriptive statistics were used to report the mean values (with standard deviation (SD)) for brain temperature and core temperature [11,12,14, $17,18,21]$ separately. Seven studies report mean (SD) differences between the sites [12-15,18-20].

In seven papers $[11,14-16,18-20]$ the study design was to show the temperature difference between brain and body. In testing for agreement of the core body temperature to perform as a measure for brain temperature, two studies only $[14,15]$ used the statistical method proposed by Bland and Altman [22,23]. With this method the spread of differences between brain and body core sites are observed and limits of agreement indicate whether 


\section{Appraisal tool:}

Reviewer:

Author:

Journal:
Date:

Year:

Record Number:

\begin{tabular}{|c|c|c|c|c|}
\hline & Yes & No & Unclear & Comments \\
\hline 1. Ethical approval? & & & & \\
\hline $\begin{array}{l}\text { 2. Patients: Were the patients' diagnosis Traumatic } \\
\text { Brain Injury only? }\end{array}$ & & & & \\
\hline $\begin{array}{l}\text { 3. Patients: Were the patients' GCS } \leq 8 \text { during } \\
\text { recruitment? }\end{array}$ & & & & \\
\hline $\begin{array}{l}\text { 4. Patients: Were the participants more than } 18 \\
\text { years old? }\end{array}$ & & & & \\
\hline $\begin{array}{l}\text { 5. Temp: Were comparisons of temperature } \\
\text { performed? }\end{array}$ & & & & \\
\hline 6. Temp: Were thermometers calibrated? & & & & \\
\hline $\begin{array}{l}\text { 7. Temp: Were all temperature measurements } \\
\text { carried out concurrently or immediately } \\
\text { sequentially? }\end{array}$ & & & & \\
\hline $\begin{array}{l}\text { 8. Temp: Were the test and reference standard } \\
\text { measured independently (blind) of each other? }\end{array}$ & & & & \\
\hline $\begin{array}{l}\text { 9. Temp: Was the second reading taken before any } \\
\text { interventions were given? }\end{array}$ & & & & \\
\hline $\begin{array}{l}\text { 10. Temp: Was there evidence of a systematic order } \\
\text { of the temperature measurement? }\end{array}$ & & & & \\
\hline $\begin{array}{l}\text { 11. Methodology: Are the outcomes measured in a } \\
\text { reliable way? }\end{array}$ & & & & \\
\hline $\begin{array}{l}\text { 12. Methodology: Is sample representative of } \\
\text { patients in the population as a whole? }\end{array}$ & & & & \\
\hline $\begin{array}{l}\text { 13. Methodology: Are the patients at a similar point } \\
\text { in the course of their condition/illness? }\end{array}$ & & & & \\
\hline $\begin{array}{l}\text { 14. Methodology: Was appropriate statistical } \\
\text { analysis used? }\end{array}$ & & & & \\
\hline
\end{tabular}

Overall appraisal: Include Exclude Seek further info

Comments (including reasons for excluding): 


\section{Extraction Tool}

\begin{tabular}{ll}
\hline Reviewer: & Date: \\
Author: & Year: \\
Journal: & Record Number: \\
\hline
\end{tabular}

Study Method:

\section{Participants: Setting:}

Population:

Sample size:

Interventions:

\begin{tabular}{|l|l|l|}
\hline & Brain Temperature & Core temperature \\
\hline $\begin{array}{l}\text { Total number of } \\
\text { measurements }\end{array}$ & & \\
\hline Measurement device & & \\
\hline Measurement site & & \\
\hline Type of thermometers & & \\
\hline Mean & & \\
\hline Standard deviation & & \\
\hline Range & & \\
\hline
\end{tabular}

Differences in mean:

Differences in SD:

Range of difference:

Correlation coefficient (if applicable):

Authors Conclusions:

Comments:

Figure 2. Extraction tool. Data were extracted from papers included in the review using a bespoke data extraction tool. 


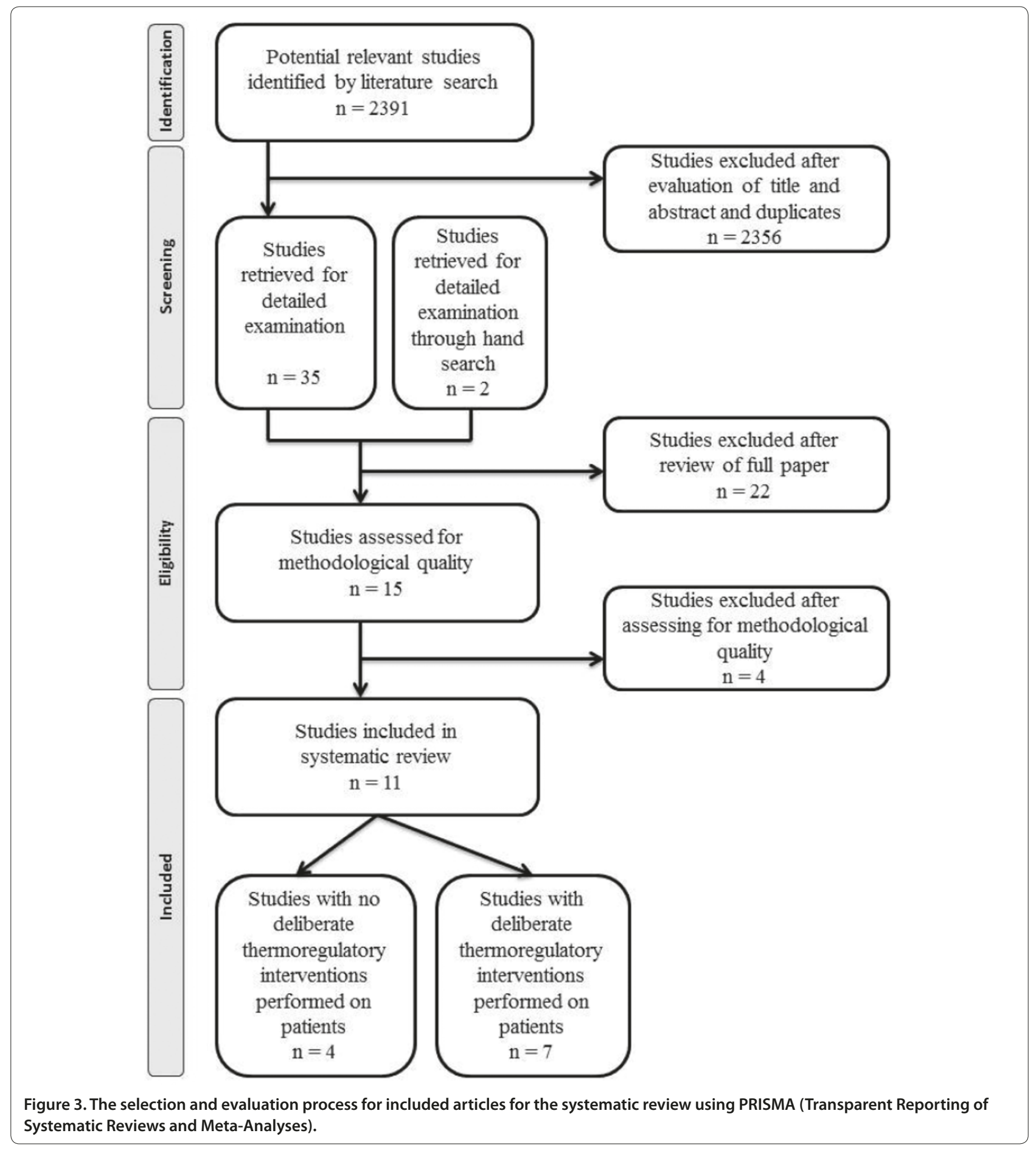

core temperature 'under-estimates' or 'over-estimates' brain temperature readings. Another study [19] calculated individual differences between brain and body (rectal) sites to produce an overall group mean with $95 \%$ CI using a random effects meta-analysis method. The remaining studies reported mean (SD) of differences only.

Four studies report temperature values incidental to a different study objective. For example, efficacy of therapeutic temperature interventions (for example, whole body cooling to induce hypothermia) $[12,13,17,21]$ on brain and body temperature. Here, agreement between the two measurement sites was not tested; rather, mean (SD) only were reported. The results of this systematic review are presented as a narrative summary to address the review objective; whether brain temperature is higher, lower, or the same as core body temperature in patients with severe TBI. 
Table 2. Differences between brain and body temperature $\left({ }^{\circ} \mathrm{C}\right)$ measurement sites for studies under review

\begin{tabular}{|c|c|c|c|c|c|}
\hline Reference & $\begin{array}{l}\text { Core body } \\
\text { temperature } \\
\text { measurement site }\end{array}$ & $\begin{array}{l}\text { Number } \\
\text { of } \\
\text { patients }\end{array}$ & $\begin{array}{l}\text { Thermoregulatory interventions } \\
\text { (target temperature) }\end{array}$ & $\begin{array}{l}\text { Mean difference } \\
(\mathrm{SD})\left({ }^{\circ} \mathrm{C}\right)\end{array}$ & $\begin{array}{l}\text { 95\% confidence } \\
\text { interval }\end{array}$ \\
\hline Rumana et al. [18] & Rectal & 30 & No thermoregulatory interventions & $1.1(0.6)$ & $(0.89 \text { to } 1.31)^{\mathrm{a}}$ \\
\hline Zhang et al. [21] & Rectal & $18^{b}$ & No thermoregulatory interventions & $0.8^{c}$ & \\
\hline Childs et al. [19] & Rectal & 19 & No thermoregulatory interventions & $-0.04(0.9)$ & $(-0.13$ to 0.05$)$ \\
\hline Puccio et al. [17] & Rectal & 21 & No thermoregulatory interventions & $-0.4^{c}$ & \\
\hline Kirk et al. [14] & Tympanic membrane & $20^{\mathrm{b}}$ & No thermoregulatory interventions & $0.9(0.7)$ & $(0.59 \text { to } 1.21)^{\mathrm{a}}$ \\
\hline Kirk etal. [14] & Temporal artery & $20^{\mathrm{b}}$ & No thermoregulatory interventions & $0.3(0.4)$ & $(0.12 \text { to } 0.48)^{\mathrm{a}}$ \\
\hline Kuo et al. [15] & Temporal artery & $28^{b}$ & No thermoregulatory interventions & $0.64(0.60)$ & $(0.42 \text { to } 0.86)^{\mathrm{a}}$ \\
\hline Kuo et al. [15] & Rectal & $28^{b}$ & No thermoregulatory interventions & $0.23(0.45)$ & $(0.06 \text { to } 0.40)^{\mathrm{a}}$ \\
\hline Henker et al. [16] & Bladder & $6^{b}$ & $\begin{array}{l}\text { Induced hypothermia therapy using } \\
\text { hypothermia blankets, iced water lavage, } \\
\text { and decreased ventilator circuit temperature } \\
\left(\mathrm{T}_{\mathrm{b}}: 32.0 \text { to } 33.0^{\circ} \mathrm{C}\right)\end{array}$ & $1.0(0.7)^{c}$ & \\
\hline Henker et al. [16] & Rectal & $8^{\mathrm{b}}$ & $\begin{array}{l}\text { Induced hypothermia therapy using } \\
\text { hypothermia blankets, iced water lavage, } \\
\text { and decreased ventilator circuit temperature } \\
\left(\mathrm{T}_{\mathrm{b}}: 32.0 \text { to } 33.0^{\circ} \mathrm{C}\right)\end{array}$ & $0.8(0.8)^{c}$ & \\
\hline Zhang et al. [21] & Rectal & $18^{b}$ & $\begin{array}{l}24 \text { hours after induced hypothermia therapy } \\
\text { using cooler blankets } \\
\left(T_{r}: 31.5 \text { to } 34.9^{\circ} \mathrm{C}\right)\end{array}$ & $1.1^{c}$ & \\
\hline Soukup et al. [12] & Rectal & $58^{d}$ & $\begin{array}{l}\text { Induced hypothermia therapy } \\
\left(\mathrm{T}_{\mathrm{br}}<36.0^{\circ} \mathrm{C}\right)\end{array}$ & $-0.2(0.6)$ & $(-0.24 \text { to }-0.16)^{a}$ \\
\hline Tokutomi et al. [13] & Rectal & $31^{b}$ & $\begin{array}{l}\text { Induced hypothermia therapy using water- } \\
\text { circulating blankets } \\
\left(\mathrm{T}_{\mathrm{br}}=33.0^{\circ} \mathrm{C}\right)\end{array}$ & $0.5(0.3)$ & $(0.39 \text { to } 0.61)^{\mathrm{a}}$ \\
\hline Tokutomi et al. [13] & Jugular vein & $31^{\mathrm{b}}$ & $\begin{array}{l}\text { Induced hypothermia therapy using water- } \\
\text { circulating blankets } \\
\left(\mathrm{T}_{\mathrm{br}}=33.0^{\circ} \mathrm{C}\right)\end{array}$ & $0.3(0.3)$ & $(0.19 \text { to } 0.41)^{\mathrm{a}}$ \\
\hline Suehiro et al. [20] & Bladder & 11 & $\begin{array}{l}\text { Induced hypothermia therapy using water- } \\
\text { cooling blankets } \\
\left(\mathrm{T}_{\mathrm{br}}=36.0 \text { to } 37.5^{\circ} \mathrm{C}\right)\end{array}$ & $-0.17(0.02)$ & $(-0.18 \text { to }-0.16)^{a}$ \\
\hline Zhang et al. [21] & Rectal & $18^{b}$ & $\begin{array}{l}\text { Induced normothermia using cooler } \\
\text { blankets } \\
\left.\text { ( } \mathrm{T}_{\mathrm{r}}: 36.5 \text { to } 37.0^{\circ} \mathrm{C}\right)\end{array}$ & $1.4^{c}$ & \\
\hline Soukup et al. [12] & Rectal & $58^{d}$ & $\begin{array}{l}\text { Spontaneous normothermia } \\
\left(\mathrm{T}_{\mathrm{br}}: 36.0 \text { to } 37.5^{\circ} \mathrm{C}\right)\end{array}$ & $0.0(0.5)$ & $(-0.02 \text { to } 0.02)^{a}$ \\
\hline Puccio et al. [17] & Rectal & 21 & $\begin{array}{l}\text { Induced normothermia using intravascular } \\
\text { cooling catheters } \\
\left(\mathrm{T}_{\mathrm{r}}: 36.0 \text { to } 36.5^{\circ} \mathrm{C}\right)\end{array}$ & $-0.1^{c}$ & \\
\hline Fischer et al. [11] & Bladder & 7 & $\begin{array}{l}\text { Induced normothermia using intravascular } \\
\text { cooling device } \\
\left(T_{b l}=36.5^{\circ} \mathrm{C}\right)\end{array}$ & $0.1^{c}$ & \\
\hline Soukup et al. [12] & Rectal & $58^{d}$ & $\begin{array}{l}\text { Spontaneous hyperthermia } \\
\left(\mathrm{T}_{\mathrm{br}}>37.5^{\circ} \mathrm{C}\right)\end{array}$ & $0.3(0.5)$ & $(0.28 \text { to } 0.32)^{\mathrm{a}}$ \\
\hline Soukup et al. [12] & Rectal & $58^{d}$ & $\begin{array}{l}\text { Spontaneous hypothermia } \\
\left(\mathrm{T}_{\mathrm{br}}<36.0^{\circ} \mathrm{C}\right)\end{array}$ & $-0.8(1.4)$ & $(-1.03 \text { to }-0.57)^{\mathrm{a}}$ \\
\hline
\end{tabular}




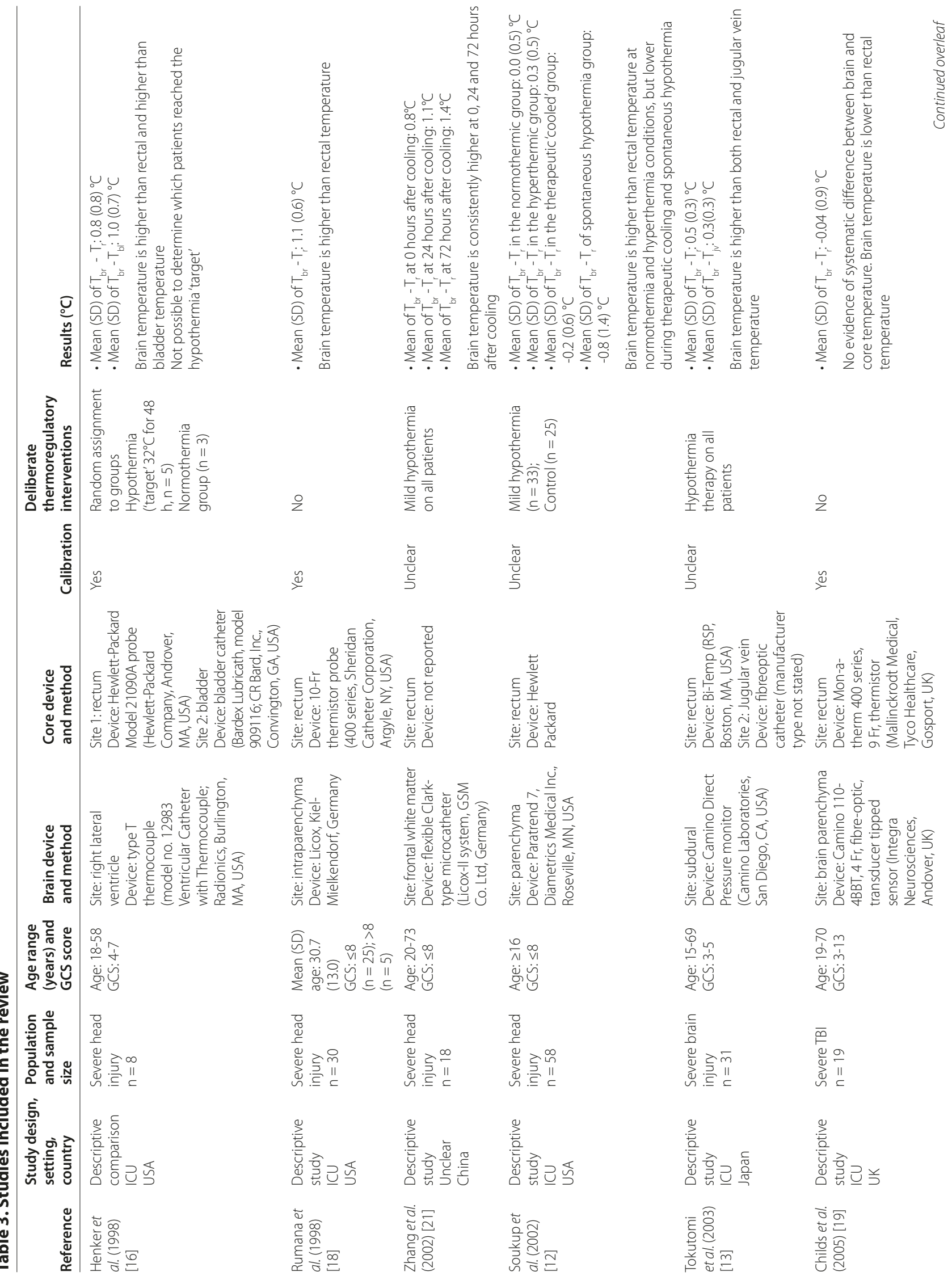




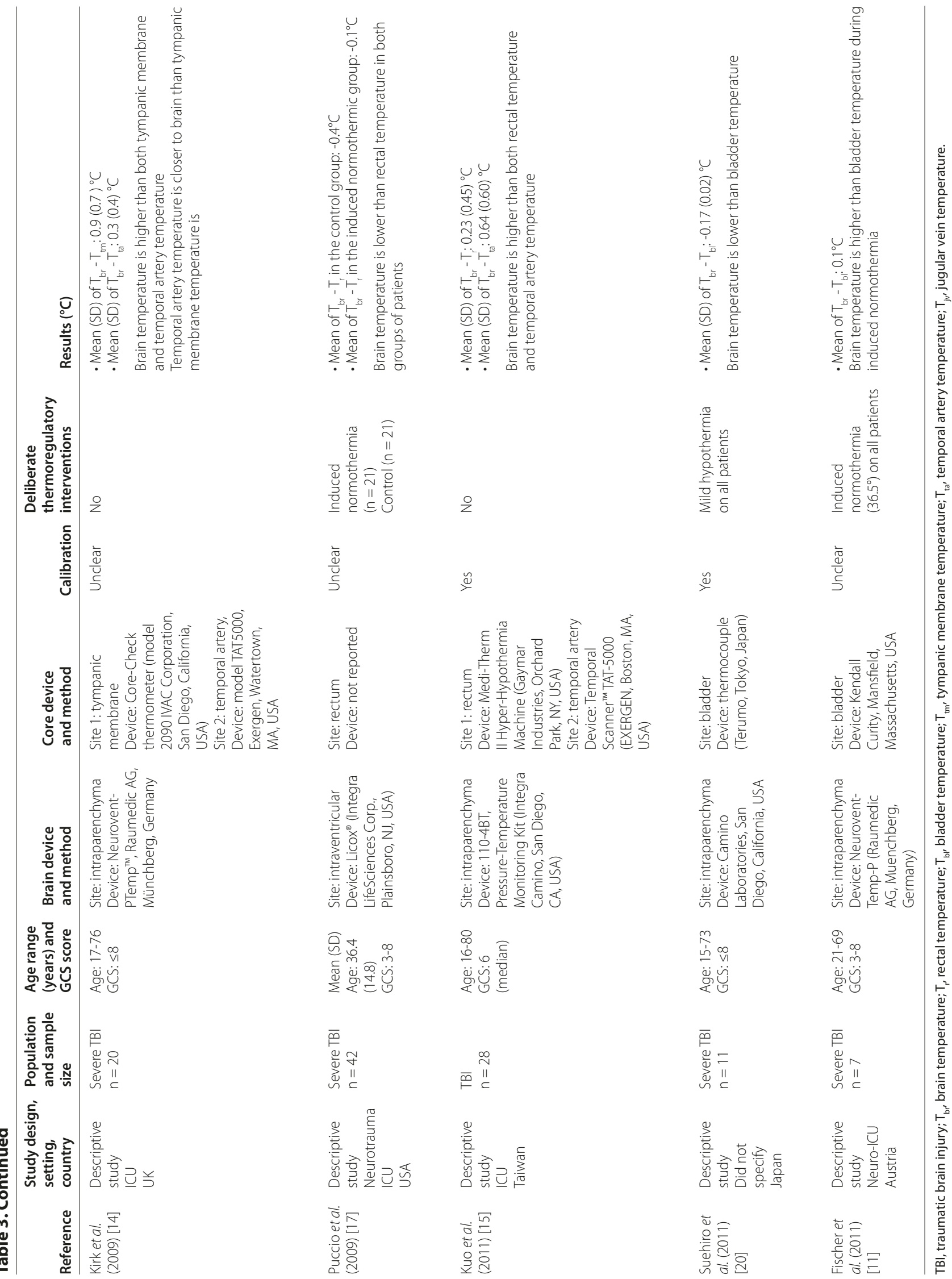




\section{Brain temperature versus rectal temperature}

Eight of eleven studies investigated the difference between brain temperature and rectal temperature [12,13,1519,21]. Patients were studied under standard care, that is, they did not receive therapeutic temperature management in three studies $[15,18,19]$. For the remainder, therapeutic temperature management to a target of normothermia [17] or mild hypothermia [13,21] was used for all study patients or for selected patients within the study cohort $[12,16]$.

Data are expressed as mean (SD). The mean difference (SD) between sites is standardised throughout the review as mean brain temperature minus mean core body temperature. A positive mean difference (MD) indicates brain temperature higher than body core temperature whereas a negative MD indicates that brain is lower than body core temperature. Data are also shown as mean (95\% CI) where values are either given by the study author [19] or calculated by the reviewer (KWL) from data available.

\section{Standard routine management}

Childs and colleagues [19] compared the difference between brain parenchyma temperature with rectal temperature in 19 patients. They report a $\mathrm{MD}$ (SD) of $-0.04^{\circ} \mathrm{C}\left(0.9^{\circ} \mathrm{C}\right)$ and a $95 \% \mathrm{CI}$ of -0.13 to 0.05 between the two sites. There was no evidence of a systematic difference between brain and core body temperature. By contrast, Rumana and colleagues [18], measuring temperature at the same sites, report a temperature $\mathrm{MD}$ (brain parenchyma-rectum) of $1.1^{\circ} \mathrm{C}\left(\mathrm{SD} 0.6^{\circ} \mathrm{C}\right)$. The $95 \%$ CI was calculated by review author KWL to be 0.89 to 1.31. This showed that mean brain temperature was more than $1^{\circ} \mathrm{C}$ higher than mean rectal temperature.

For studies where induction of normothermia was the therapeutic temperature management intervention, Puccio and colleagues [17] compared temperature measured in rectum and cerebral ventricle in two groups of patients. In one group $(n=21)$ rectal temperature was maintained at $36.5^{\circ} \mathrm{C}$ for three days while the other group received standard care (control, $\mathrm{n}=21$ ). Mean $(\mathrm{SD})$ brain temperature was $36.6^{\circ} \mathrm{C}\left(0.9^{\circ} \mathrm{C}\right)$ and $37.4^{\circ} \mathrm{C}\left(1.4^{\circ} \mathrm{C}\right)$ for normothermia and control groups, respectively. For rectal temperature, mean temperature (SD) was $36.5^{\circ} \mathrm{C}$ $\left(0.6^{\circ} \mathrm{C}\right)$ and $37.0^{\circ} \mathrm{C}\left(0.9^{\circ} \mathrm{C}\right)$. The authors did not report MD (SD) between the two sites. From the data available, author (KWL) calculated temperature MD (brain minus rectum). For both the induced normothermia and control group, the MD was slightly negative but clinically insignificant at $-0.1^{\circ} \mathrm{C}$ under conditions of normothermia. For the control group, mean brain temperature was slightly $\left(0.4^{\circ} \mathrm{C}\right)$ higher than mean rectal temperature. The CI of this study could not be calculated from data provided in the publication.

\section{Hypothermia therapy}

Tokutomi and colleagues [13] and Zhang and colleagues [21] examined the differences between brain temperature and rectal temperature in their studies, which explored the effect of mild hypothermia on brain temperature and other physiological parameters (brain tissue partial pressure of oxygen, intracranial pressure, systemic and intracranial haemodynamics, metabolism). For the former study [13], 31 patients were 'cooled' to $33^{\circ} \mathrm{C}$ followed by slow rewarming after 48 to 72 hours of hypothermia. Mean brain (subdural) temperature was consistently higher than mean rectal temperature: $\mathrm{MD} 0.5^{\circ} \mathrm{C}\left(0.3^{\circ} \mathrm{C}\right), 95 \% \mathrm{CI} 0.39$ to 0.61 .

For the 18 patients recruited by Zhang and colleagues [21] blankets were used to lower body temperature (Meditherm-Gaymar, USA) to a target (rectal) of $31.5^{\circ} \mathrm{C}$ to $34.9^{\circ} \mathrm{C}$ for between 1 and 7 days (average 58 hours). The MD (SD) of brain temperature at 0 hours, 24 hours and 72 hours after therapeutic hypothermia was $38.5^{\circ} \mathrm{C}$ $\left(1.5^{\circ} \mathrm{C}\right), 33.6^{\circ} \mathrm{C}\left(1.5^{\circ} \mathrm{C}\right)$ and $34.5^{\circ} \mathrm{C}\left(1.8^{\circ} \mathrm{C}\right)$, respectively, and the mean (SD) of rectal temperature for the same interval after hypothermia (0 hours, 24 hours, 72 hours) was $37.7^{\circ} \mathrm{C}\left(1.7^{\circ} \mathrm{C}\right), 32.5^{\circ} \mathrm{C}\left(1.2^{\circ} \mathrm{C}\right)$ and $33.1^{\circ} \mathrm{C}\left(1.5^{\circ} \mathrm{C}\right)$, respectively. No data regarding the $\mathrm{MD}$ between the two sites were provided by the authors but, from the data available, MD of brain minus rectum (calculated by KWL) at 0 hours, 24 hours, and 72 hours was $0.8^{\circ} \mathrm{C}, 1.1^{\circ} \mathrm{C}$, and $1.4^{\circ} \mathrm{C}$, respectively. The $\mathrm{CI}$ could not be calculated from data available. In this study mean brain temperature was consistently higher than mean rectal temperature at all three of the therapeutic hypothermia treatment time-points.

\section{Hypothermia therapy on selected patients}

Soukup and colleagues [12] used induction of mild hypothermia $\left(<36^{\circ} \mathrm{C}\right)$ in 25 of 33 patients. Brain-rectum MD (SD) was reported according to four different clinical situations: a normothermia group (brain temperature between $36.0^{\circ} \mathrm{C}$ and $37.5^{\circ} \mathrm{C}$ ); a hyperthermia group (brain temperature $>37.5^{\circ} \mathrm{C}$ ); a therapeutic cooling group (brain temperature $<36.0^{\circ} \mathrm{C}$ in response to therapy); and a spontaneous hypothermia group (brain temperature $<36^{\circ} \mathrm{C}$ without any active cooling or management strategy for the low temperature). In the normothermia group, MD (SD) between the two sites was $0.0^{\circ} \mathrm{C}\left(0.5^{\circ} \mathrm{C}\right), 95 \% \mathrm{CI}$ -0.02 to 0.02 (calculated by KWL). In the hyperthermia group MD (SD) between the sites was $0.3^{\circ} \mathrm{C}\left(0.5^{\circ} \mathrm{C}\right), 95 \%$ CI (calculated) 0.28 to 0.32 . In the therapeutic cooling group, $\mathrm{MD}(\mathrm{SD})$ was $-0.2^{\circ} \mathrm{C}\left(0.6^{\circ} \mathrm{C}\right), 95 \% \mathrm{CI}$ (calculated) -0.24 to -0.16 . The greatest differences in temperature (brain-rectum) was in the spontaneous hypothermia group; $\mathrm{MD}(\mathrm{SD})-0.8^{\circ} \mathrm{C}\left(1.4^{\circ} \mathrm{C}\right), 95 \% \mathrm{CI}$ (calculated by KWL) -1.03 to -0.57 . Results show that at temperatures below $36^{\circ} \mathrm{C}$ (either spontaneously or due to deliberate cooling) brain temperature is lower than core body temperature. In the study by Henker and colleagues [16], 
patients were recruited as a part of a study of therapeutic hypothermia (target temperature 32 to $33^{\circ} \mathrm{C}$ ). Five patients were randomly assigned to the hypothermia treatment group and three to the normothermia group. It is not possible from the data to identify those who received the different temperature management strategies but the range of MD (SD) between brain and rectal temperature for individual patients was 0.1 to $2.7^{\circ} \mathrm{C}$.

\section{Brain temperature versus jugular vein temperature}

Only one study [13] focused on the differences between brain (cerebral) temperature and jugular vein temperature measured at the jugular bulb. Tokutomi and colleagues [13] studied 31 patients who were cooled to $33^{\circ} \mathrm{C}$ and then slowly re-warmed after 48 to 72 hours of hypothermia. They reported a MD of $0.3^{\circ} \mathrm{C}$ and a SD of $0.3^{\circ} \mathrm{C}$ between these two sites of measurement. The calculated $95 \%$ CI of this study ranged from 0.19 to 0.41 .

\section{Brain temperature versus bladder temperature}

Henker and colleagues [16] measured brain temperature (ventricle) and bladder temperature simultaneously in eight patients. The MD between brain temperature and bladder temperature based on temperature values across three ranges $\left(\leq 36^{\circ} \mathrm{C},>36\right.$ to $\left.\leq 38^{\circ} \mathrm{C},>38^{\circ} \mathrm{C}\right)$ ranged from $0.1^{\circ} \mathrm{C}$ to $2.7^{\circ} \mathrm{C}$. A MD (SD) of $1.0^{\circ} \mathrm{C}\left(0.7^{\circ} \mathrm{C}\right)$ was calculated by KWL from the data provided. In this study determination of patients undergoing hypothermia to target temperature was not possible from the data provided.

Fischer and colleagues [11] maintained the brain temperature of seven patients at $36.5^{\circ} \mathrm{C}$ as a form of prophylactic normothermia. The mean (SD) of brain temperature was $36.4^{\circ} \mathrm{C}\left(0.5^{\circ} \mathrm{C}\right)$ while the mean $(\mathrm{SD})$ of bladder temperature was $36.3^{\circ} \mathrm{C}\left(0.4^{\circ} \mathrm{C}\right)$. The $\mathrm{MD}$ between the two sites was $0.1^{\circ} \mathrm{C}$. The $\mathrm{SD}$ of differences between the two sites was not reported. Suehiro and colleagues [20] on the other hand cooled their patients and kept the brain temperature at $33^{\circ} \mathrm{C}$ to $35^{\circ} \mathrm{C}$ for at least three days. The MD (SD) between brain temperature and bladder temperature was reported to be $-0.17^{\circ} \mathrm{C}\left(0.02^{\circ} \mathrm{C}\right)$.

Brain temperature versus tympanic membrane temperature Kirk and colleagues [14] compared brain parenchyma temperature and tympanic membrane temperature in 20 patients with severe TBI. Mean (SD) of brain temperature and tympanic membrane was $37.8^{\circ} \mathrm{C}\left(0.7^{\circ} \mathrm{C}\right)$ and $36.9^{\circ} \mathrm{C}$ $\left(0.8^{\circ} \mathrm{C}\right)$, respectively. A MD and $\mathrm{SD}$ of $0.9^{\circ} \mathrm{C}\left(0.7^{\circ} \mathrm{C}\right)$ was reported between the two measurement sites. The $95 \%$ CI of this study ranged from 0.59 to 1.21 , as calculated by KWL.

\section{Brain temperature versus temporal artery temperature} In the same paper, Kirk and colleagues [14] also investigated the difference between brain and temporal artery temperature. Mean (SD) temporal artery temperature was $37.5^{\circ} \mathrm{C}\left(0.5^{\circ} \mathrm{C}\right)$. MD (SD) between brain parenchyma temperature and temporal artery temperature was $0.3^{\circ} \mathrm{C}$ $\left(0.4^{\circ} \mathrm{C}\right)$ with $95 \% \mathrm{CI}$ of 0.12 to 0.48 , as calculated by KWL. In addition to comparing brain temperature with rectal temperature under standard conditions (MD between the two temperature measurement sites of $0.23^{\circ} \mathrm{C}, \mathrm{SD}$ $0.45^{\circ} \mathrm{C}$ ), Kuo and colleagues [16] also compared brain and temporal artery temperature. The authors report a MD of $0.64^{\circ} \mathrm{C}$ and a $\mathrm{SD}$ of $0.60^{\circ} \mathrm{C}$. Temporal artery temperature may lead to underestimation of brain temperature.

\section{Discussion}

Problems in the interpretation of results are evident because there is, as yet, no consensus of what value constitutes a clinically relevant difference between brain and body temperature [24]. From a pragmatic viewpoint, it would be fair to assume that measurement differences that exceed the manufacturer's stated accuracy for the thermistor (typically $\pm 0.2^{\circ} \mathrm{C}$ ) would be the smallest difference that could be expected. However, and assuming all sensors have a manufacturer's stated accuracy of this order, and taking into consideration 'real' measurement differences, a value of $0.2^{\circ} \mathrm{C}$ might be the minimum difference that one could propose as a clinically significant measurement difference between brain and core body sites. Implicit in such an assumption, however, is the need to be certain that measurements at both brain and core sites are 'true'. For example, whilst sensors inserted into the brain are less likely to be dislodged, it is appreciated clinically that core body measurements can be unreliable; rectal thermometry being a good example. In the event that the thermistor slips from its optimum position $10 \mathrm{~cm}$ into the rectum, readings will be influenced greatly by 'external' factors. This type of measurement error, although common, is frequently overlooked, and would lead to an underestimation of brain temperature; not due to tissue temperature differences per se but rather to erroneous core body temperature readings and poor measurement practice.

There remains no consensus on the reliability of 'core' body temperature as a surrogate measure of the temperature of healthy or injured human brain despite concerns being raised and efforts made to tackle the issue [24]. Neurocritical care research represents a field of active and lively scientific and clinical investigation with respect to altered thermal homeostatic and physiological derangements after severe TBI. This is particularly relevant to the ongoing debate as to the benefits, or otherwise, of therapeutic temperature management (for example, moderate hypothermia of 33 to $34^{\circ} \mathrm{C}$ ). Whilst temperature at one or more sites may be reported as a secondary finding, prospective studies to determine the 'true' difference in temperature 'inside' versus 'outside' 
the head are clearly inconclusive. As a result, the clinician must inevitably base decisions on common assumption rather than robust evidence for practice. This is not ideal in the setting of neurocritical care since a rise in the temperature of injured neurones is considered to carry a higher risk for accelerated secondary brain damage. Of interest to this current systematic review is the observation that the largest average temperature differences occur under conditions of hypothermia, irrespective of the measurement sites used for temperature monitoring.

Average core body temperature ranges from $1.4^{\circ} \mathrm{C}$ above brain temperature to almost $1.0^{\circ} \mathrm{C}$ below brain temperature. Some healthy scepticism is warranted here with respect to measurement error. Whilst the techniques for insertion of single, dual or multiple sensor placement are typically robust (via a fixed skull bolt), this is not the case for sensors placed on or within the body. For example, rectal temperature measurement has the potential to be a very good surrogate for brain temperature as shown by Childs and colleagues [19] but if the thermistor slips from the insertion site, measurements will be unreliable. Bowel movements, position, turning and personal care are all factors that could cause the sensor to 'fall out'. Clinical experience tells us that physiological range rectal temperatures are common even with the sensor lying under (rather than inside) the patient's body. Under such circumstances, sensor displacement would lead to a temperature reading artefact and a false increase in brain temperature compared to body temperature. For other core body sites, reliability of measurement has been called into question, especially with regard to tympanic thermometry [14] and especially if local regions are 'contaminated' by the effects of skin (or internal, such as bladder) cooling.

In the present series, two studies [18,19] adopted similar study designs in a group of patients with severe TBI. Measurements of brain parenchyma and core body (rectal) temperature were made under standard routine care without any deliberate thermoregulatory interventions. The results reported on brain-body temperature differences are polar and, at first sight, without any obvious explanation. Childs and colleagues [19] showed that there was no systematic difference between brain parenchyma and rectal temperature, whilst Rumana and colleagues [18] found a mean difference of $1.1^{\circ} \mathrm{C}$. Adding some weight to the observation, at least for the reliability of rectal temperature, is the evidence that rectal temperature readings were comparable to 'gold' standard measurements of core temperature measured in blood, albeit venous (jugular vein). As a consequence, results show that rectal temperature is at least as reliable as blood temperature. Moreover, results from Rumana and colleagues [18] suggest that jugular vein temperature reflects body rather than brain temperature.
There are a number of factors that might be postulated to account for the difference in results between the studies by Childs and colleagues [19] and Rumana and colleagues [18]. Despite recruiting patients of the same diagnosis (severe TBI) with GCS score $\leq 8$, both studies measured brain temperature and core temperature under 'standard care.' However, 'standard care' can differ across institutions, and country practice may vary considerably. Early versus late surgery, and pharmacological and nonpharmacological interventions for high or low temperature are two examples of the variations that might exist in each institution's 'standard care'. In addition, certain pharmacological treatments, such as administration of paracetamol or non-steroidal antiinflammatory drugs (NSAIDs), can have a major impact on thermoregulation. Complete reporting of standard care and/or full interventions is not common practice, principally due to limitations in manuscript word count. Institutional variations can occur but, broadly, neurocritical management practices are similar and follow Brain Trauma Foundation Guidelines [25].

The same issues are evident where therapeutic temperature interventions have been used. Here, the discrepancy between the two temperature measurement sites is larger but it is not clear whether this is due to effects of the intervention per se or differences elsewhere, such as the severity and nature of the injury or subtle differences in the clinical management of the patient. Whatever the reason for the somewhat larger difference reported between the temperature sites under hypothermic conditions, the results of this systematic review suggest that when brain temperature falls below $36.0^{\circ} \mathrm{C}$, either by deliberate body cooling or spontaneously as a consequence of the injury, the dissociation between brain-body temperature widens by as much as $1.5^{\circ} \mathrm{C}$ in either direction. Therefore, extra caution should be exercised when therapeutic temperature interventions are ongoing because using core body temperature as a surrogate or 'proxy' for brain temperature may become less reliable compared to normothermic conditions.

The results from this systematic review differ from the literature review of Mcilvoy [26], who concluded that brain temperature is predominantly higher than body temperature. Here, the main difference is the patient population. Mcilvoy [26] included patients with various neurological injuries (stroke, tumour, hydrocephalus, TBI) while the current systematic review focuses only on patients with severe TBI. It is well recognised that the pathophysiology of various neurological injuries such as stroke, brain trauma and intracerebral haemorrhage differ and this may explain why there is a lack of agreement between previous reviews and the current review, particularly as the two papers $[17,19]$ showing brain temperature lower than body temperature were 
published after the review of Mcilvoy [26] was published.

\section{Limitations}

This systematic review sourced publications in English only. Non-English publications with relevant information may have been missed. To aid synthesis of information, it was necessary to develop an appraisal tool specifically for the purpose of this review. An appraisal tool for method comparison studies used in a previously published systematic review was modified for use in investigating the temperature differences between brain and body sites. This modified critical appraisal tool has not been subjected to peer review or tested for validity under the conditions of the current review.

As noted in the discussion, seven studies only of the included publications specifically set out to determine the agreement between brain and body temperature. Temperature calibration formed a component of the methodological investigation, but only five studies clearly indicated calibration was done for their thermometer before commencing data collection. For the remainder of the studies it is not clear if thermometers were calibrated or if measurement reliability was checked. Similarly, these studies did not report sufficient statistical information, showing no more than the mean values with standard deviation of the differences. Relevant statistical analyses were not done to test statistical agreement between the two measurement sites. With the exception of one study that was powered to show a difference between the two measurement sites, the remaining studies adopted convenience sampling; sample sizes were small only. Therefore, generalisation of the results should be viewed with caution.

Brain temperature was measured at one of three sites (parenchyma, ventricle, and subdural space) in this systematic review. It has been noted that brain temperature may vary across different sites of the brain $[27,28]$. Whilst the evidence is sparse, comparisons between different brain sites compared to different core body sites is a further source of inconsistency in measurement. Temperature measured at the tip of the thermistor in situ and irrespective of brain site has been regarded as 'brain' temperature for the purposes of this systematic review but issues regarding the site of measurement and differences in temperature values at damaged versus undamaged sites could have a bearing on the brain temperature reading. As shown using magnetic resonance spectroscopic techniques for absolute temperature measurement [29] in experimental (non-human primate) stroke, highest values were observed in the ischaemic penumbra, values higher than in the contralateral (unaffected) region and ischaemic core [30]. Such findings suggest a potential explanation for the variations between study groups, possibly on the basis of evolution of the primary injury to infarction. As too is the possibility of the role of haem products due to haemorrhage when traumatic subarachnoid haemorrhage may co-exist with tissue injury, so exacerbating inflammation (and local heat production) in the brain [31].

\section{Conclusion}

The results of this systematic review show that core body temperature (measured at various sites of the body) is not a reliable 'proxy' for brain temperature in patients with severe TBI. Hence, the use of body temperature to predict brain temperature is not advisable in the clinical setting. Direct brain measurement is still the best way to monitor brain temperature in patients with severe traumatic brain injury.

\section{Abbreviations}

$\mathrm{Cl}$, confidence interval; GCS, Glasgow Coma Score; JBI, Joanna Briggs Institute; $M D$, mean difference; $R C T$, randomised controlled trial; $S D$, standard deviation; $\mathrm{TBI}$, traumatic brain injury.

\section{Competing interests}

The authors declare that they have no competing interests.

\section{Acknowledgements}

We would like to thank Dr Melanie Attard and Dr Christina Hagger from the Joanna Briggs Institute for their kind help and assistance in the initial drafts where the online version of the review is available at the JBI Library of Systematic Reviews (www.joannabriggs.edu.au/).

\section{Authors contributions}

CC conceived of the review topic, participated in the evaluation, data extraction and synthesis and drafted the manuscript and wrote the final draft. KWL undertook the searching, participated in the evaluation, data extraction and synthesis and co-drafted the manuscript. Both authors read and approved the final manuscript.

\section{Author details}

'Clinical Research Centre, Block MD11, Level 2, Yong Loo Lin School of Medicine, National University of Singapore, 10 Medical Drive, Singapore 117597. 2National University Hospital, 5 Lower Kent Ridge Road, Singapore 119074.

Published: 22 April 2013

\section{References}

1. Benzinger T: Heat regulation: homeostasis of central temperature in man. Physiol Rev 1969, 49:671-753.

2. Mellergard $\mathrm{P}$, Nordstrom C, Christensson M: A method for monitoring intracerebral temperature in neurosurgical patients. Neurosurgery 1990, 27:654-657.

3. Nursing Management of Adults with Severe Traumatic Brain Injury: AANN Clinical Practice Guideline Series [http://www.aann.org/pdf/cpg/ aanntraumaticbraininjury.pdf]

4. Thompson HJ, Tkacs NC, Saatman KE, Raghupathi R, McIntosh TK: Hyperthermia following traumatic brain injury: a critical evaluation. Neurobiol Dis 2003, 12:163-173.

5. Lee KK, Seow WT, Ng I: Demographical profiles of adult severe traumatic brain injury patients: implications for healthcare planning. Singapore Med J 2006, 47:31-36.

6. Childs C: Human brain temperature: regulation, measurement and relationship with cerebral trauma: part 1. Br J Neurosurg 2008, 22:486-496.

7. Johnston NJ, King AT, Protheroe R, Childs C: Body temperature management after severe traumatic brain injury: methods and protocols used in the United Kingdom and Ireland. Resuscitation 2006, 70:254-262. 
8. Kueh WL, Childs C: A systematic review of differences between brain temperature and core body temperature in adult patients with severe traumatic brain injury. JBI Library Systematic Rev 2012, 10:1410-1451.

9. Crowder CM, Tempelhoff R, Theard MA, Cheng MA, Todorov A, Dacey RG Jr: Jugular bulb temperature: comparison with brain surface and core temperatures in neurosurgical patients during mild hypothermia. $J$ Neurosurg 1996, 85:98-103.

10. Craig JV, Lancaster GA, Williamson PR, Smyth RL: Temperature measured at the axilla compared with rectum in children and young people: systematic review. Br Med J 2000, 320:1174-1178.

11. Fischer M, Lackner P, Beer R, Helbok R, Klien S, Ulmer H, Pfausler B, Schmutzhard E, Broessner G: Keep the brain cool - endovascular cooling in patients with severe traumatic brain injury: a case series study. Neurosurgery 2011, 68:867-873; discussion 873.

12. Soukup J, Zauner A, Doppenberg EM, Menzel M, Gilman C, Young HF, Bullock $R$ : The importance of brain temperature in patients after severe head injury: relationship to intracranial pressure, cerebral perfusion pressure, cerebral blood flow, and outcome. J Neurotrauma 2002, 19:559-571.

13. Tokutomi T, Morimoto K, Miyagi T, Yamaguchi S, Ishikawa K, Shigemori M: Optimal temperature for the management of severe traumatic brain injury: effect of hypothermia on intracranial pressure, systemic and intracranial hemodynamics, and metabolism. Neurosurgery 2003, 52:102-111.

14. Kirk D, Rainey T, Vail A, Childs C: Infra-red thermometry: the reliability of tympanic and temporal artery readings for predicting brain temperatuer after severe traumatic brain injury. Crit Care 2009, 13:R81.

15. Kuo JR, Lo CJ, Wang CC, Lu CL, Lin SC, Chen CF: Measuring brain temperature while maintaining brain normothermia in patients with severe traumatic brain injury. J Clin Neurosci 2011, 18:1059-1063.

16. Henker RA, Brown SD, Marion DW: Comparison of brain temperature with bladder and rectal temperatures in adults with severe head injury. Neurosurgery 1998, 42:1071-1075.

17. Puccio AM, Fischer MR, Jankowitz BT, Yonas H, Darby JM, Okonkwo DO: Induced normothermia attenuates intracranial hypertension and reduces fever burden after severe traumatic brain injury. Neurocrit Care 2009, 11:82-87

18. Rumana CS, Gopinath SP, Uzura M, Valadka AB, Robertson CS: Brain temperature exceeds systemic temperature in head-injured patients. Crit Care Med 1998, 26:562-567.

19. Childs C, Vail A, Protheroe R, King AT, Dark PM: Differences between brain and rectal temperatures during routine critical care of patients with severe traumatic brain injury. Anaesthesia 2005, 60:759-765.

20. Suehiro E, Fujisawa H, Koizumi H, Nomura S, Kajiwara K, Fuji M, Suzuki M: Significance of differences between brain temperature and core temperature (delta T) during mild hypothermia in patients with diffuse axonal injury. Neurol Med Chir (Tokyo) 2011, 51:551-555.
21. Zhang S, Zhi D, Lin X, Shang Y, Niu Y: Effect of mild hypothermia on partial pressure of oxygen in brain tissue and brain temperature in patients with severe head injury. Chin J Traumatol 2002, 5:43-45

22. Bland JM, Altman DG: Statistical methods for assessing agreement between two methods of clinical measurement. Lancet 1986, 1:307-310.

23. Altman DG, Bland JM: Measurement in medicine: the analysis of method comparison studies. J R Stat Soc Series D (The Statistician) 1983, 32:307-317.

24. Childs C, Wieloch T, Lecky F, Machin G, Harris B, Stocchetti N: Report of a consensus meeting on human brain temperature after severe traumatic brain injury: its measurement and management during pyrexia. Front Neurol 2010, 1:146.

25. Bullock MR, Povlishock JT: Guidelines for the management of severe traumatic brain injury. Editor's Commentary. J Neurotrauma 2007, 24 Suppl $1: 2 \mathrm{p}$ preceding $\mathrm{S} 1$.

26. Mcilvoy L: Comparison of brain temperature to core temperature: a review of the literature. J Neurosci Nurs 2004, 36:23-31.

27. Fountas KN, Kapsalaki EZ, Feltes CH, Smisso HF, Johnston KW, Robinson JS: Intracranial temperature - Is it different throughout the brain? Neurocrit Care 2004, 1:195-199.

28. Mellergård P: Intracerebral temperature in neurosurgical patients: Intracerebral temperature gradients and relationships to consciousness level. Surg Neurol 1995, 43:91-95.

29. Childs C, Hiltunen Y, Vidyasagar R, Kauppinen RA: Determination of regional brain temperature using proton magnetic resonance spectroscopy to assess brain-body temperature differences in healthy human subjects. Magn Reson Med 2007, 57:59-66.

30. Sun Z, Zhang J, Chen Y, Zhang Y, Zhang X, Guo H, Yu C: Differential temporal evolution patterns in brain temperature in different ischemic tissues in a monkey model of middle cerebral artery occlusion. J Biomed Biotechnol 2012, 2012:980961

31. Greenhalgh AD, Brough D, Robinson EM, Girard S, Rothwell NJ, Allan SM: Interleukin-1 receptor antagonist is beneficial after subarachnoid haemorrhage in rat by blocking haem-driven inflammatory pathology. Dis Model Mech 2012, 5:823-833.

doi:10.1186/cc11892

Cite this article as: Childs C, Kueh WL.: Clinical review; Brain-body temperature differences in adults with severe traumatic brain injury. Critical Care 2013, 17:222. 


\section{Appraisal tool:}

Reviewer:

Date:

Author:

Year:

Journal:

Record Number:

1. Ethical approval?

2. Patients: Were the patients' diagnosis Traumatic Brain Injury only?

3. Patients: Were the patients' GCS $\leq 8$ during recruitment?

4. Patients: Were the participants more than 18 years old?

5. Temp: Were comparisons of temperature performed?

6. Temp: Were thermometers calibrated?

7. Temp: Were all temperature measurements carried out concurrently or immediately sequentially?

8. Temp: Were the test and reference standard measured independently (blind) of each other?

9. Temp: Was the second reading taken before any interventions were given?

10. Temp: Was there evidence of a systematic order of the temperature measurement?

11. Methodology: Are the outcomes measured in a reliable way?

12. Methodology: Is sample representative of patients in the population as a whole?

13. Methodology: Are the patients at a similar point in the course of their condition/illness?

14. Methodology: Was appropriate statistical analysis used?

\begin{tabular}{|l|l|l|l|}
\hline Yes & No & Unclear & Comments \\
\hline & & & \\
\hline & & & \\
\hline & & & \\
\hline & & & \\
\hline & & & \\
\hline & & & \\
\hline & & & \\
\hline & & & \\
\hline & & & \\
\hline & & & \\
\hline & & & \\
\hline & & & \\
\hline & & & \\
\hline & & & \\
\hline & & & \\
\hline & & & \\
\hline & & & \\
\hline & & & \\
\hline & & & \\
\hline & & & \\
\hline & & & \\
\hline & & & \\
\hline & & & \\
\hline & & & \\
\hline
\end{tabular}

Overall appraisal:

Include

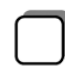

Exclude

Seek further info

Comments (including reasons for excluding): 
Reviewer:

Author:

Journal:

Study Method:

Participants: Setting:

Population:

Sample size:

Interventions:

\begin{tabular}{|l|l|l|}
\hline & Brain Temperature & Core temperature \\
\hline $\begin{array}{l}\text { Total number of } \\
\text { measurements }\end{array}$ & & \\
\hline Measurement device & & \\
\hline Measurement site & & \\
\hline Type of thermometers & & \\
\hline Mean & & \\
\hline Standard deviation & & \\
\hline Range & & \\
\hline
\end{tabular}

Differences in mean:

Differences in SD:

Range of difference:

Correlation coefficient (if applicable):

Authors Conclusions:

Comments:
Date:

Year:

Record Number: 
Potential relevant studies identified by literature search

$$
\mathrm{n}=2391
$$

Studies retrieved for detailed examination

$$
\mathrm{n}=35
$$

Studies retrieved for detailed examination through hand search $\mathrm{n}=2$

Studies assessed for methodological quality $\mathrm{n}=15$

Studies excluded after assessing for methodological quality $\mathrm{n}=4$

Studies included in systematic review $\mathrm{n}=11$

Studies excluded after review of full paper $\mathrm{n}=22$

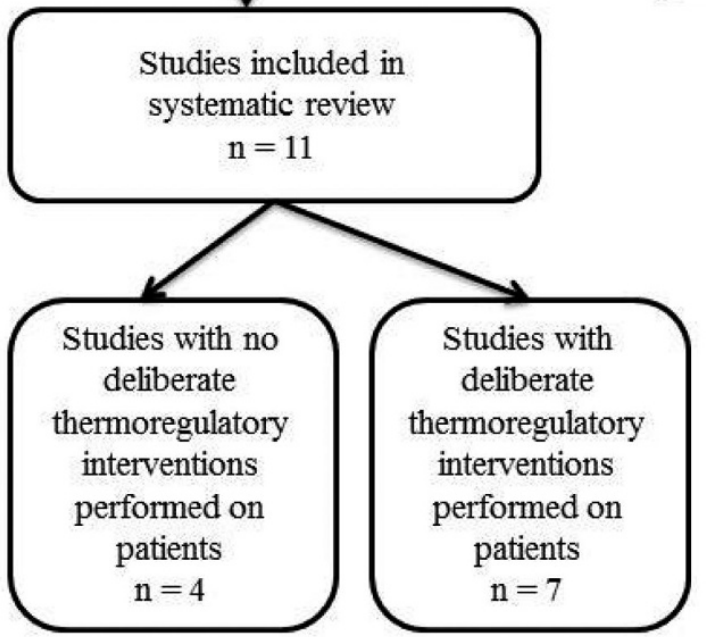

Studies excluded after evaluation of title and abstract and duplicates $\mathrm{n}=2356$ 